\title{
Development and Implementation of a Nordic Grid Model for Power System Small-Signal and Transient Stability Studies in a Free and Open Source Software
}

\author{
Yuwa Chompoobutrgool, Student Member, IEEE, Wei Li, Luigi Vanfretti, Member, IEEE.
}

\begin{abstract}
This article presents an implementation of a Nordic grid model in Power System Analysis Toolbox (PSAT) - a free and open-source software. A newly developed hydro turbine and hydro governor (HTG) model is implemented with this grid model and compared with the currently available PSAT turbine governor models. Small-signal and transient stability analyses of the system using the two models are carried out and compared to demonstrate the difference and necessity of accurate hydro turbine and governor model utilization. The paper ends with a validation of the linearized Nordic grid model generated by PSAT including the newly implemented HTG models. This validation is done through nonlinear time-domain simulation by applying both large and small disturbances.
\end{abstract}

Index Terms-Power system modelling; nordic power system; hydro turbine modelling; hydro governor modelling; small-signal stability; inter-area oscillations

\section{INTRODUCTION}

Responses of an electric power network after disturbances portray the dynamic behavior of the system. Understanding dynamic responses is crucial in evaluating the system's characteristics. Once these characteristics have been well-understood, the response of the system to disturbances may be anticipated, and unwanted behavior can be alleviated by the design and implementation of power system controls and protections.

Stability of a power system is dependent on the set of parameters describing the dynamic properties of each of its elements. Of particular importance are those parameters belonging to machines, e.g. generators, turbines, and/or governors. They play a major role in rotor angle stability which is classified into two types: small-signal stability and transient stability [1]. These two types of stability are widely and intensively employed for stability security assessment at network control centers and for planning purposes.

To correctly forecast dynamic responses and assess system stability, accurate modelling of power systems is highly important. The system model should be capable of representing the

\footnotetext{
Manuscript submitted to the IEEE PES General Meeting Conference, 2012.

Y. Chompoobutrgool, W. Li, and L. Vanfretti are with the Electric Power Systems Division, School of Electrical Engineering, Royal Institute of Technology (KTH), Teknikringen 33, SE-100 44, Stockholm, Sweden. E-mail: yuwa@kth.se, liwei.emma@gmail.com, luigiv@kth.se

Y. Chompoobutrgool is supported by Elforsk, Sweden.

W. Li was supported in part by EIT InnoEnergy Collocation Center Sweden within the "Smart Power" thematic area.

L. Vanfretti is supported by the STandUP for Energy collaboration initiative and the KTH School of Electrical Engineering.
}

behavior of the real system as close as possible. Incorrect or incomplete modelling may lead to incorrect simulation results, which could in turn result in costly consequences in operation.

The Nordic electricity network has the characteristics of bearing heavy generation in the northern region while supplying large consumption in the southern region through weak transmission lines [2]. The northern region is largely supplied by hydro power and the southern region by thermal generation. Features of hydro generators are substantially different from those of thermal generators, and their respective modelling needs to be done appropriately.

Previous research on the Nordic grid system has been extensively carried out on proprietary simulation software such as PSS ${ }^{\circledR}$ E [3], PacDyn [4], and SIMPOW ${ }^{\circledR}$ [5]. Some sample studies include wide-area monitoring and control [6], [7], [8], wide-area damping control [9], [10], and linear analysis [11]. Some of these software are only capable of simulating one type of stability analysis and require different dynamic models; this is the case in [10] where PSS ${ }^{\circledR} \mathrm{E}$ is used for transient stability simulations while PacDyn is used for smallsignal stability analysis. The main disadvantage here is that the non-linear PSS ${ }^{\circledR} \mathrm{E}$ model used for transient simulations may not necessarily correspond to the PacDyn linearized model used for the studies. As a result, controllers designed using PacDyn's linear model may not perform satisfactorily when simulated using the nonlinear PSS ${ }^{\circledR} \mathrm{E}$ model. In addition, while these models developed for the analysis of the Nordic grid are useful, they have been implemented in proprietary software packages. High cost, license restrictions, and limited freedom of core software modifications are the hurdles of the type of proprietary software. On the other hand, to the authors' knowledge, none of the Free and Open Source Software (FOSS) alternatives has been utilized for the modelling of the Nordic grid. Hence, an attractive alternative would be to utilize a free and open source power system software that encompasses both transient and small-signal models.

Proprietary software are conceived by the general public to be well-tested, trustworthy, and computationally efficient. Note that this perception might not be necessarily true for all software [12]. More importantly, license agreements restrict the use of proprietary software by imposing different conditions; in other words, they are "closed" [13]. On the other hand, free and open source software allow users to change the source code, add new algorithms, and/or implement new 
components ${ }^{1}$. Unlike the proprietaries, FOSS give users the "freedom" and liberty which is the key difference between the two software. In addition, free software stands on an ethical pillar which aims to warrant intrinsic freedoms of computer users that are jeopardized by proprietary software [12], [14].

Power System Analysis Toolbox (PSAT) [15] is an educational open source software for power system analysis studies [16]. The toolbox covers fundamental and necessary routines for power system studies such as power flow, smallsignal stability analysis, and time-domain simulation. PSAT is a suitable candidate as a power system analysis software which is capable of performing core stability analyses. There is, however, one limitation: hydro turbine and governors models were not available in the toolbox.

The aim of this paper is, therefore, to propose an improved model of the modified Nordic power system for power system stability analyses and studies. The improved model includes a newly developed hydro turbine and hydro governor model [17] which is capable of representing the actual dynamic behaviour of hydro units. Not only will this allow for a more accurate representation of the system's dynamic behavior but also allows for the analysis of small-signal and transient stability studies. Consequently, suitable controls can be properly designed to limit the negative impact of inter-area oscillations and other instabilities.

\section{KTH-NORDIC32 SYSTEM}

\section{A. Background}

The system analyzed in this study is a conceptualization of the Swedish power system and its neighbors circa 1995. It is based on a system data set proposed by T. Van Cutsem [18], which is a variant of the CIGRE "Nordic 32A" test network developed by K.Walve [19]. Due to some adjustment to the system model and its parameters, the system in this study is called KTH-NORDIC32.

\section{B. System Characteristics}

The KTH-NORDIC32 system is depicted in Fig. 1. The overall topology is longitudinal; two large regions are connected through considerably weak transmission lines. The first region is formed by the North and the Equivalent areas located in the upper part, while the second region is formed by the Central and the South areas located in the bottom part. The system has 52 buses, 52 transmission lines, 28 transformers and 20 generators, 12 of which are hydro generators located in the North and the Equivalent areas, whereas the rest are thermal generators located in the Central and the South areas. There is more generation in the upper areas while more loads congregate in the bottom areas, resulting in a heavy power transfer from the northern area to the southern area through weak tie-lines.

\footnotetext{
${ }^{1}$ Free and open source software is usually distributed on-line "cost free" The word "free" in this context is focused not in cost but rather in respecting the software users' freedoms outlined in [12].
}

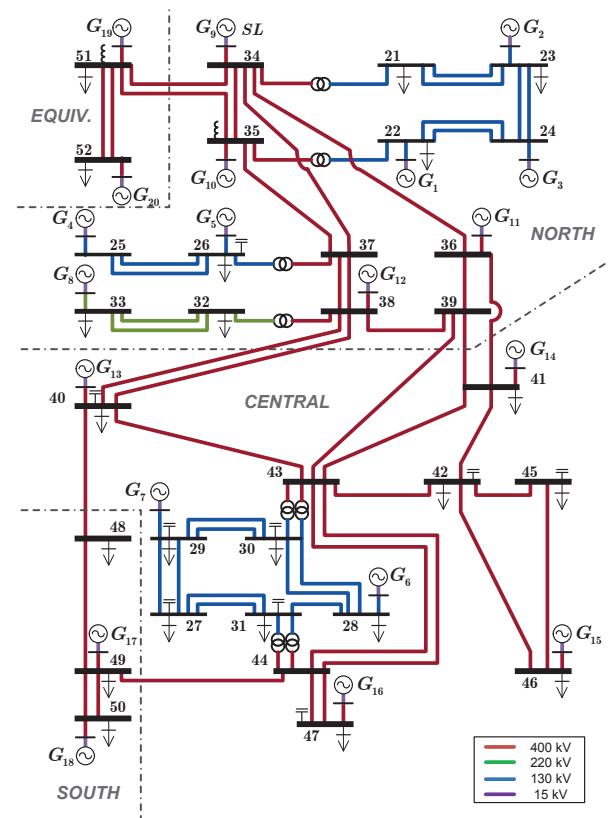

Fig. 1. KTH-NORDIC32 Test System

\section{Dynamic Modelling}

Dynamic models of synchronous generators, exciters, turbines, and governors for the improved Nordic power system are implemented in PSAT. All models used are documented in the PSAT Manual. Parameter data for the machines, exciters, and turbine and governors are referred to [18], [19] and provided in Appendix B.

1) Generator Models: Two synchronous machine models are used in the system: three-rotor windings for the salientpole machines of hydro power plants and four-rotor windings for the round-rotor machines of thermal plants. According to Fig. 1, thermal generators are denoted by $G_{6}, G_{7}$ and $G_{13}$ to $G_{18}$ whereas hydro generators are denoted by $G_{1}$ to $G_{5}$, $G_{8}$ to $G_{12}, G_{19}$ and $G_{20}$. These two types of generators are described by five and six state variables, respectively: $\delta, \omega$, $e_{q}^{\prime}, e_{q}^{\prime \prime}, e_{d}^{\prime \prime}$, and with an additional state $e_{d}^{\prime}$ for the six-statevariables machine. All generators have no mechanical damping and saturation effects are neglected.

2) Automatic Voltage Regulator and Over Excitation Limiter Models: The same model of AVR, as shown in Fig. 2, is used for all generators but with different parameters. The field voltage $v_{f}$ is subject to an anti-windup limiter.

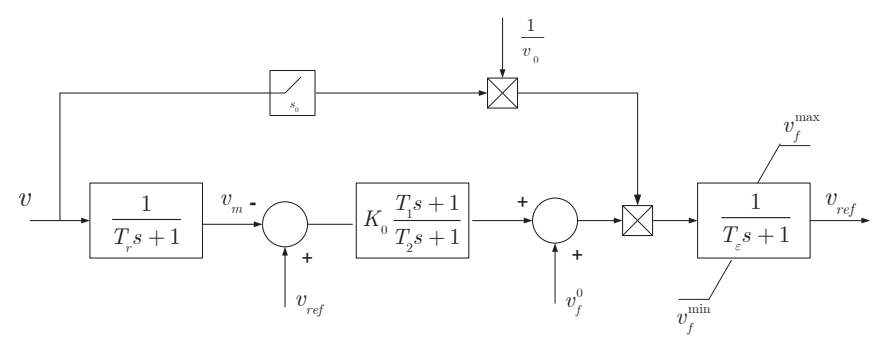

Fig. 2. Exciter Model

The model of over excitation limiters (OEL) used in the system is shown in Fig. 3. A default value of $10 \mathrm{~s}$ is used 
for the integrator time constant $T_{0}$, while the maximum field current was adjusted according to each field voltage value so that the machine capacity is accurately represented.

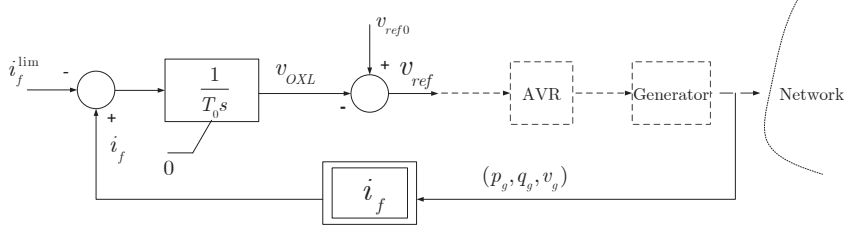

Fig. 3. Over Excitation Limiter Model

3) Turbine and Governor Models: In PSAT there are two models of turbine and governors; namely Model 1 and Model 2: the former being a thermal generator model while the latter a simplified model. As such, the system's hydro generator is temporarily represented by Model 2 while that of the thermal is represented by Model 1. Block diagrams of turbine and governor models for Model 1 and Model 2 are depicted in Fig. 4 and 5, respectively.

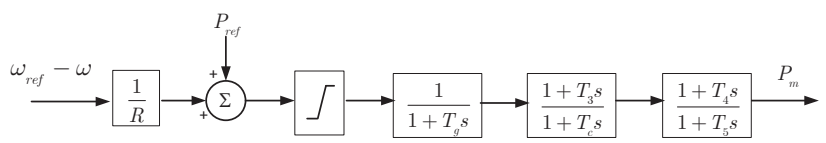

Fig. 4. Turbine Governor Model used for thermal generators: Model 1

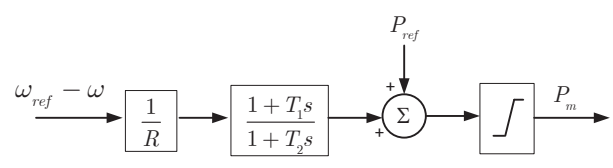

Fig. 5. Turbine Governor Model used for hydro generators: Model 2

\section{Hydro TURBInE AND GOVERNOR IMPLEMENTATION}

As of 2010, hydro power plants contributed nearly to $50 \%$ of the electricity production in Sweden [20]. As such, modelling dynamic characteristics of hydro generators, particularly in this Nordic system model, is of significance. The reason is that features of hydro generators are substantially different from those of thermal generators. Using only available turbine and governor models in PSAT (Model 1 and 2) to represent the hydro machines is inaccurate. This and the following sections will illustrate this modelling issue.

One important characteristics of hydro generators which distinguishes it from the others is the "water hammer effect" [21], [22]. That is, when the water gate opens in response to a load increase, the water pressure at the gate initially reduces due to a sudden increase in the volume of water, but, after a moment, it will increase afterwards (and vice versa for a load decrease).

\section{A. Hydro Turbine and Governor Modelling}

$\mathrm{Li}, \mathrm{W}$. et al. recently developed hydro turbine and governor (HTG) models in PSAT [23]. The block diagram of one of the models, Model 3, is shown in Fig. 6. The block consists of a typical hydro turbine governor and a linearized hydro turbine model where the corresponding elements are depicted in the figure. The linearized turbine is the classical hydro turbine model in power system stability analysis, corresponding to ideal turbine and inelastic penstock with water inertial effect considered.

Hydro turbines and their governors are normally combined together for representation. However, in some cases, the output of the turbine is the derivative of gate position $(\Delta G)$ while the input to the turbine is the gate position $G$. As such, a gate position reference, $G_{r e f}$, is required between $\Delta G$ and $G$. Note that the number of state variables introduced by this model is equal to the total number of integrators.

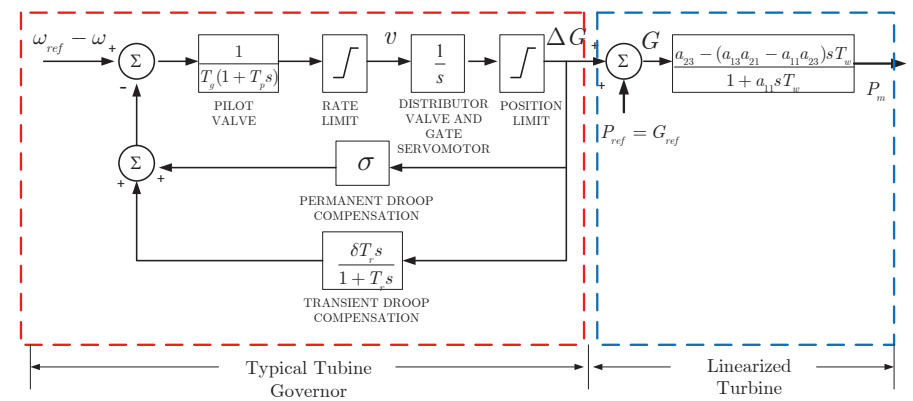

Fig. 6. Turbine and Governor Model used for hydro generators: Model 3

\section{B. Hydro Turbine and Governor Simulation}

To illustrate the real behavior of HTGs, pole-zero maps of the turbine and governor of $G_{1}$ using Model 2 and Model 3 are shown in Fig. 7a and 7b, respectively. In addition, responses of the mechanical power $P_{m 20}$ to a $10 \%$ load change at Bus 52 , where the hydro generator $G_{20}$ is connected, using Model 2 and Model 3 as HTG are compared in Fig. 8. Note that the load change is applied at $\mathrm{t}=2 \mathrm{~s}$ and simulated for $20 \mathrm{~s}$.

In Fig. $7 \mathrm{~b}$, it can be seen that there exists one zero in the right-half plane while a drop in $P_{m 20}$ before rising to meet the load increase can be noticed in Fig. 8b. This feature is a characteristic of nonminimum phase systems, which, for hydro generator, corresponds to its dominant characteristics: the water hammer effect. On the contrary, Model 2 in Fig. 7a or 8a (the blue line) fails to capture this effect, and thus, is not suitable as a representative model of HTGs.

The parameters of the hydro turbine and governor used in Model 3 are provided in Appendix B.

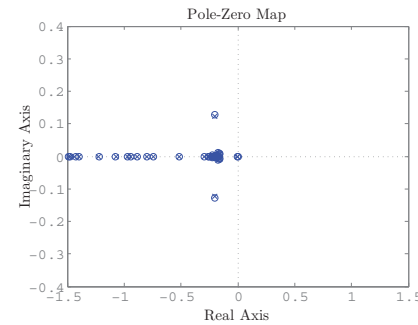

(a) Model 2

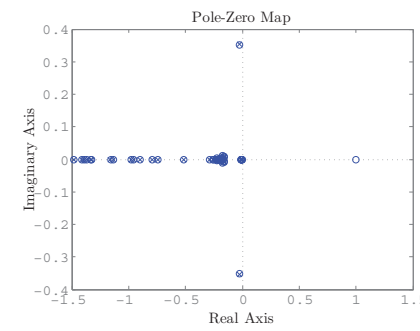

(b) Model 3
Fig. 7. Pole-Zero maps for turbine and governor models of $G_{1}$. 


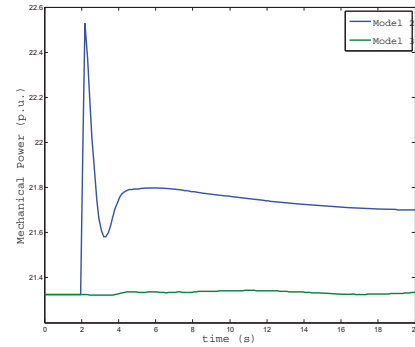

(a) Model 2 vs. Model 3

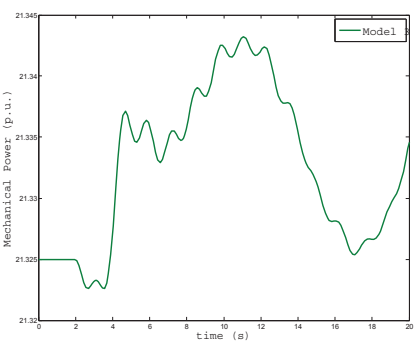

(b) Model 3 (enlargement)
Fig. 8. Response of the mechanical power $P_{m 20}$ to a $10 \%$ load change at Bus $G_{52}$

\section{RESUlts AND ANALYSES}

This section illustrates the main differences between the system behaviors in two cases: the use of Model 2 and Model 3 as HTGs in the KTH-NORDIC32 test system, and affirms why accurate modelling of hydro turbine and governor is necessary. As previously discussed, Model 2 is unsuitable and is used here for comparison purpose only. Note that Model 1 is used to represent thermal generators in both cases.

\section{A. Small-Signal Stability Analysis}

Small-signal stability is defined as the ability of a power system to maintain its synchronism after being subjected to a small disturbance [1]. Small-signal stability analysis reveals important relationships among state variables of a system and gives an insight into the electromechanical dynamics of the network.

Eigenanalysis, a well-established linear-algebra analysis method [24], is employed to determine the small-signal dynamic behavior of the study system. Applying the technique to the linearized model of the KTH-NORDIC32 system, smallsignal stability is studied by analyzing four properties: eigenvalues, frequency of oscillation, damping ratios and eigenvectors (or mode shapes). Stability of a system depends on the sign of the real part of eigenvalues; if there exists any positive real part, that system is unstable. The frequency of oscillation is derived from the imaginary part of eigenvalues while the damping ratio is derived from the real part. Damping ratios indicate "how" stable a system is; the higher the (positive) value of a damping ratio, the more stable the system is for a given oscillation. For instance, a low (but positive) damping ratio implies that, although the system is stable, the system is more prone to instability than other systems having higher damping ratios.

Eigenvalues of the KTH-NORDIC32 system implementing Model 2 and Model 3 are illustrated in Fig. 9a and 9b, as well as their corresponding local enlargement depicted in Fig. 9c- 9d, respectively. Comparing Fig. 9c to Fig. 9d, it can be observed that there are more eigenvalues having lower damping ratios in the system with Model 3 than that with Model 2. The system has 223 states with Model 2 and 259 states with Model 3; the number corresponds to the same number of eigenvalues. The system is stable for both cases.

Small-signal stability issues are mainly associated with insufficient generator damping. Of particular interest are those having low frequency of oscillations. These types of oscillations, namely low-frequency inter-area oscillations (LFIO), occur in large power systems interconnected by weak transmission lines [25] that transfer heavy power flows. The system of study, KTH-NORDIC32, has the characteristics of bearing heavy power flow from the northern region supplying the load in the southern region through loosely connected transmission lines. Consequently, the system exhibits lightly damped low frequency inter-area oscillations. Table I provides the two lowest damping modes, their corresponding frequencies and damping ratios, and the most associated state variables for both cases. As shown in the table, the damping ratios obtained from the two models bear a significant difference. This discrepancy is due to the incorrect modelling of the HTGs using Model 2, for which damping ratios are larger than when using Model 3 for HTG representation. This model error might influence the design of damping controllers to be less effective; this precisely illustrates why HTG modelling is important.

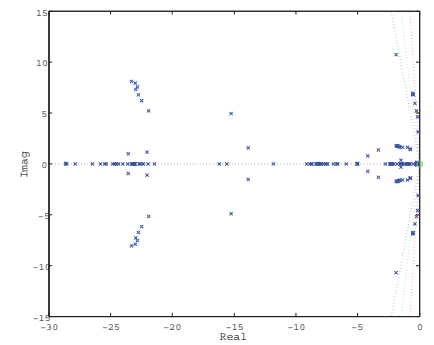

(a) Model 2

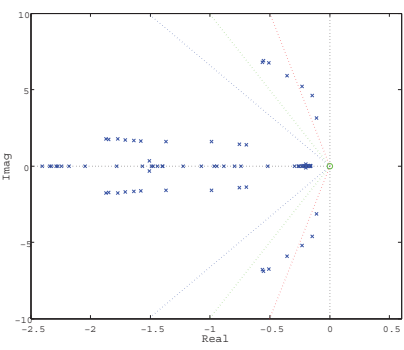

(c) Model 2 (local enlargement)

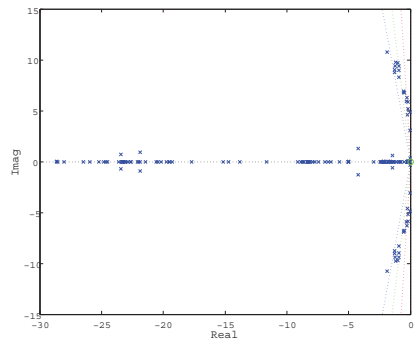

(b) Model 3

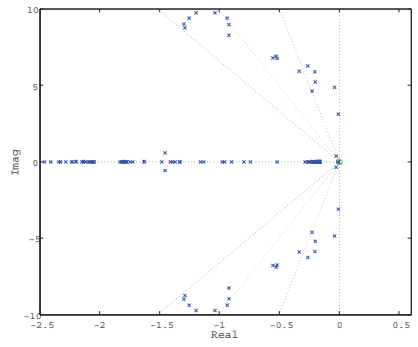

(d) Model 3 (local enlargement)
Fig. 9. Eigenvalues of the KTH-NORDIC32 system.

Mode shapes, or the right eigenvectors, give an insight into the relative activity of state variables in each mode. Within a mode, the larger the magnitude of the mode shape element, the more observable that state variable is. In this study, mode shapes of the generator speed, $\omega_{i}$, is used for analysis as shown in Fig. 10 and 11 for the test system employing Model 2 and Model 3 as HTGs, respectively. It can be observed that $\omega_{18}$ is the most observable in Mode 1 whereas $\omega_{6}$ is the most observable in Mode 2 of both models. These observations will later be useful in input signal selection for damping control design.

\section{B. Transient Stability Analysis}

Transient stability is defined as the ability of a power system to maintain its synchronism after being subjected to a severe (or large) disturbance [1]. One of the most commonly used means to assess the transient stability of a power system is 
TABLE I

LINEAR ANALYSIS RESULTS OF THE TWO LOWEST DAMPING MODES IN KTH-NORDIC32

\begin{tabular}{|c||c|c|c|c|}
\hline Model & Eigenvalues & Frequency $(\mathrm{Hz})$ & Damping ratio & Most associated states \\
\hline \hline System with Model 2 & $-0.11043 \pm j 3.1331$ & 0.49866 & 0.035223 & $\omega_{18}, \delta_{18}$ \\
& $-0.14637 \pm j 4.6004$ & 0.73218 & 0.031801 & $\omega_{6}, \delta_{6}$ \\
\hline System with Model 3 & $-0.0061875 \pm j 3.1015$ & 0.49362 & 0.0019950 & $\omega_{18}, \delta_{18}$ \\
& $-0.039918 \pm j 4.8658$ & 0.77442 & 0.0082036 & $\omega_{20}, \delta_{20}$ \\
\hline
\end{tabular}

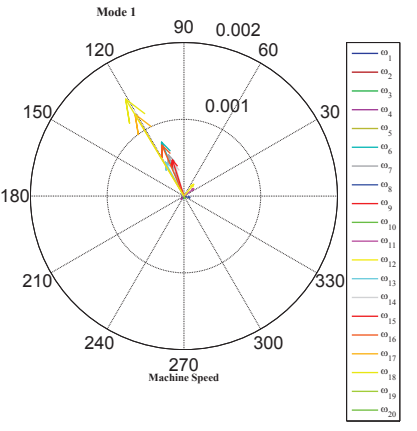

(a) Mode 1: $0.49866 \mathrm{~Hz}$

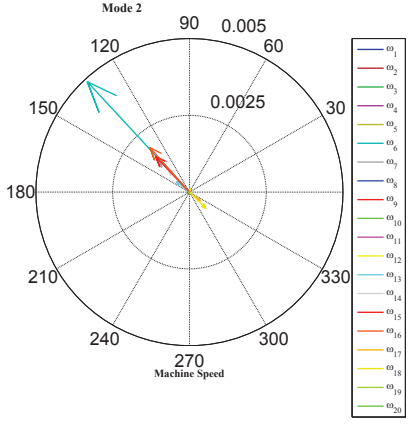

(b) Mode 2: $0.73218 \mathrm{~Hz}$
Fig. 10. Mode shapes of the KTH-NORDIC32 system implementing Model 2 .

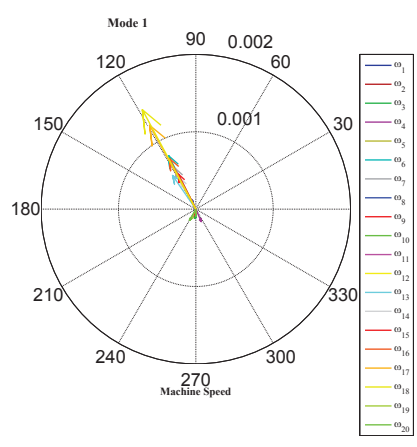

(a) Mode 1: $0.49362 \mathrm{~Hz}$

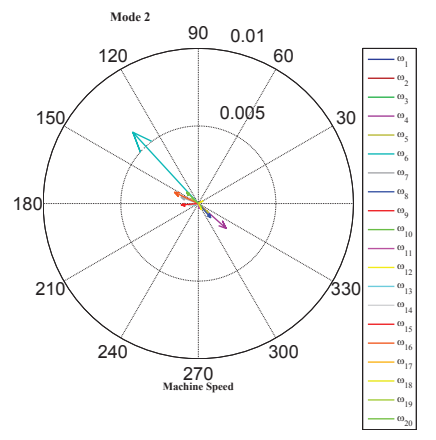

(b) Mode 2: $0.77442 \mathrm{~Hz}$
Fig. 11. Mode shapes of the KTH-NORDIC32 system implementing Model 3.

to apply a fault at a node and observe the corresponding responses. To allow for a proper comparison of the performance of the two models of turbine and governor, the fault should be applied at a bus in such way that the nonlinear behavior of the model can be evaluated. As such, a three-phase fault is applied at Bus 1011 at $t=5 \mathrm{~s}$ and removed after $20 \mathrm{~ms}$ in this study. The generator speed responses of the two models, Model 2 and Model 3, are displayed in Fig. 12a and 12b, respectively. Note that during approximately the first $10 \mathrm{~s}$ of the simulation, the responses of the system using Model 3 exhibit the nonlinear characteristics of the model.

Comparing the two simulations, the two responses behave considerably different; those of Model 2 converge to steady state while those of Model 3 show larger damped oscillations. This is due to the system's damping related to the inter-area swings [26], [27], [28]. Note that with this disturbance, both Mode 1 and Mode 2, discussed in the previous section, are excited.

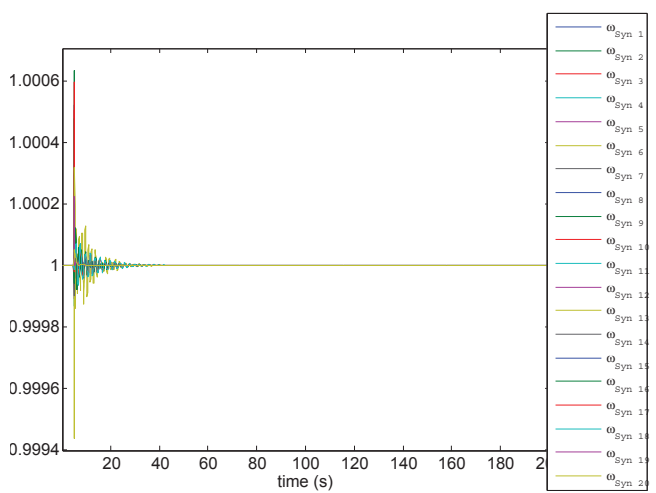

(a) Model 2 Implementation.

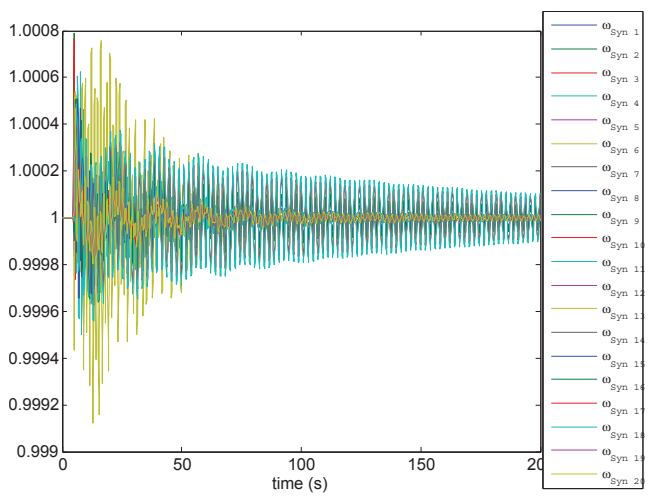

(b) Model 3 Implementation.

Fig. 12. KTH-NORDIC32 system responses to a fault.

\section{Linear Model Validation through Nonlinear TIME-DOMAIN SimUlation}

Power systems are nonlinear in nature as such their behavior is difficult to analyze. To simplify analysis of electromechanical oscillations (which are the primary concern), linearization techniques can be applied to the nonlinear system as shown in Section IV-A. To verify how well the linearized model represents the behavior of the nonlinear model under the linear-operating region where the model has been linearized, the linear models can be validated by: 1) verifying the linear properties from time-domain responses due to small perturbations and/or 2) tracking the response to control input changes. As such, the following three studies are conducted on the linearized model of the KTH-NORDIC32 system. In the studies below, Model 1 is implemented as thermal turbine and governors and Model 3 as hydro turbine and governors.

\section{A. Fault Occurrence}

To capture the general behavior of the KTH-NORDIC32 system, one approach is to apply a three-phase fault at a bus as a perturbation and study the dynamic response from 
a time-domain simulation. A similar fault is applied to the same bus with the same duration as in the previous section on transient stability analysis. The fast Fourier transform (FFT) is employed to identify the prominent frequency components in the frequency domain. Based on the small-signal studies in Section IV, the state variables $\omega_{6}$ and $\omega_{18}$ are of our interests and their corresponding FFTs are depicted in Fig. 13a and 13b, respectively.

As shown in the figures, there are two primary frequency components: 0.49438 and $0.77515 \mathrm{~Hz}$, as well as an inconspicuous frequency at $0.057983 \mathrm{~Hz}$. The two primary frequencies belong to system electromechanical oscillations, which correspond to the two lowest damping inter-area oscillations, while the other smaller frequency is caused by turbine/governor dynamics. These results are in accordance with those of the small-signal studies (see Table I) where $0.49-\mathrm{Hz}$ mode is dominated by the dynamics of $G_{18}$ and $0.77-\mathrm{Hz}$ mode by that of $G_{6}$. It is thus demonstrated here that the responses of the nonlinear time-domain simulation do capture the same dominant modes as the linear analysis does.

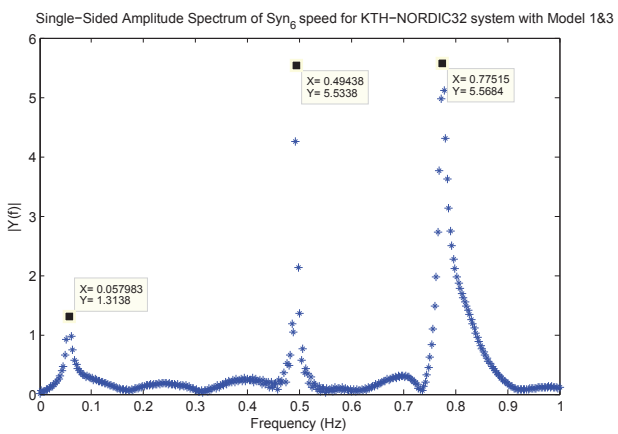

(a) FFT on $\omega_{6}$

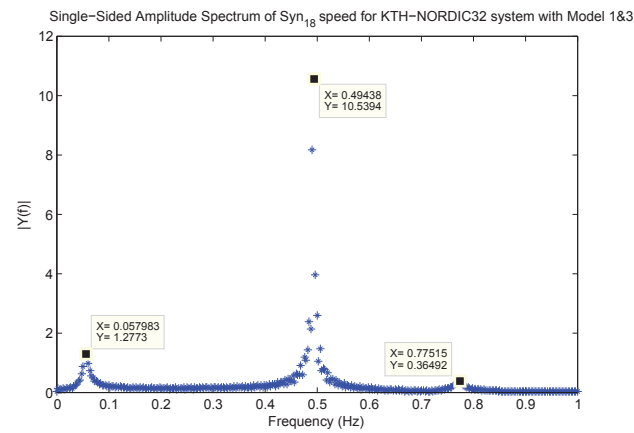

(b) FFT on $\omega_{18}$

Fig. 13. FFT on rotor speed signals of the linearized KTH-NORDIC32 system.

\section{B. Disturbance at AVR's Reference Voltage}

To assess the effects of controllers, such as power system stabilizers (PSS), on the system behavior, a perturbation is applied at the AVR's reference voltage $\left(V_{\text {ref }}\right)$ since the PSS output modifies the AVR's reference voltage. The perturbation here is a $2 \%$ step change in $V_{\text {ref }}$ of the AVR at $G_{2}$ at $t=1 \mathrm{~s}$ and is simulated for $20 \mathrm{~s}$. Two parallel simulations are conducted: a time-domain simulation to investigate the nonlinear model response and a time response of the linearized system. Both responses are analyzed and compared to validate the consistency of the system model. Note that over excitation limiters are removed to avoid changes in the AVR's reference voltage.

The comparison between nonlinear and linear simulations at generator terminal voltages $V_{6}$ and $V_{18}$ are depicted in Fig. 14a and $14 \mathrm{~b}$, respectively. As seen from the figures, the results of both methods are consistent with each other. Although not shown here, using the FFT technique, the dominant frequencies in $V_{6}$ and $V_{18}$ responses are approximately 0.49 , 0.79 and $0.06 \mathrm{~Hz}$ which correspond to system oscillations and turbine/governor dynamics, respectively. Both results capture the dominant mode of concern and are coherent with each other.

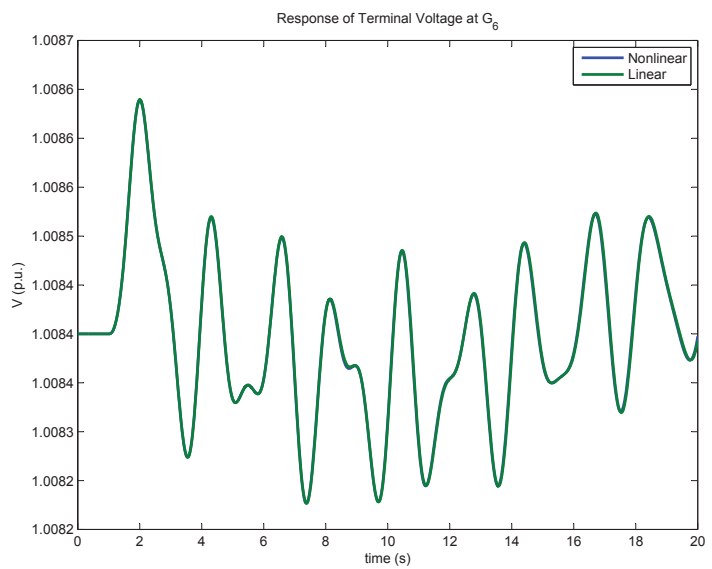

(a) Terminal Voltage Responses at $G_{6}$

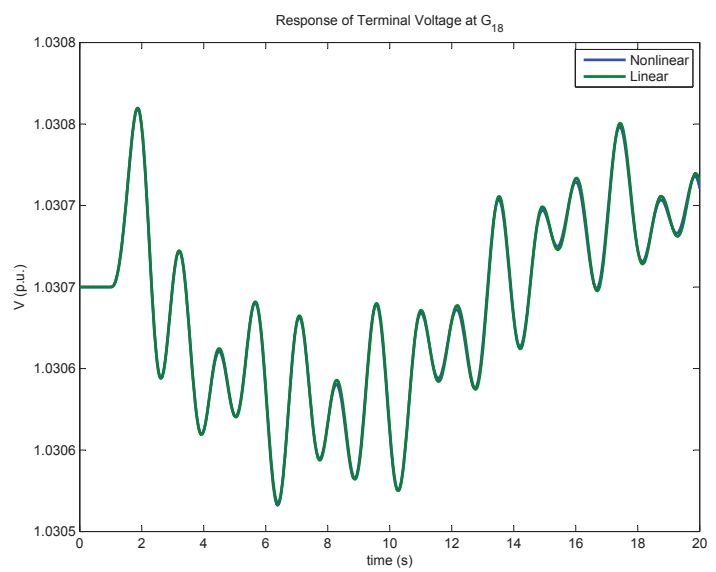

(b) Terminal Voltage Responses at $G_{18}$.

Fig. 14. Responses after applying a perturbation at the voltage reference of $G_{2}$.

\section{Disturbance at Governor's Reference Speed}

To assess the effects of turbine and governors on the system behavior, a perturbation is applied at the governor's speed reference $\left(\omega_{\text {ref }}\right)$. The perturbation is a $0.05-\mathrm{Hz}$ step change in $\omega_{\text {ref }}$ of $G_{2}$ at $t=1 \mathrm{~s}$ and is simulated for $20 \mathrm{~s}$. Similar to the previous section, a time-domain simulation is compared with a time response of the linearized system. As shown in 
Fig. 15, both linear and nonlinear responses of the mechanical power at $G_{18}$ are in accordance with each other.

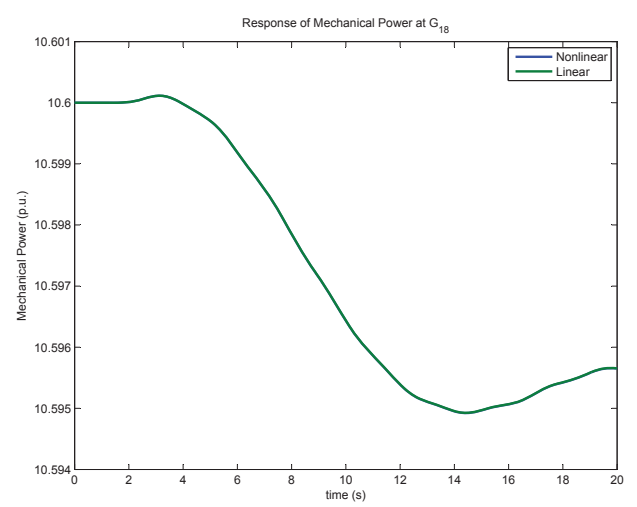

Fig. 15. Mechanical Power outputat $G_{18}$.

\section{Conclusion And Future Work}

This paper presents the Nordic grid model of which the novelty being its implementation in a free and open source software; namely, Power System Analysis Toolbox (PSAT). The model takes into account detailed modelling of the dynamics which play an important role in the assessment of the system's behavior. Of particular significance is the implementation of the recently developed hydro turbine and governor (HTG) model in PSAT with the Nordic test system since more than half of the grid's generators are hydro power plants. This HTG model is capable of representing the true characteristics of hydro generators: the water hammer effect which translates into nonminimum phase characteristics. To demonstrate the importance of accurate modelling, stability analyses (small-signal and transient) of the Nordic grid model utilizing the HTG are compared with the test system employing the existing turbine governor models in PSAT. The discrepancies between the two models emphasize such necessity. Finally, the validation of the linearized Nordic grid model by nonlinear time-domain simulations is carried out. The results give confidence in the linear models generated with the inclusion of the new HTG model for its use in controller design, in particular, for inter-area oscillation damping which, was illustrated in the small-signal analysis section.

\section{ACKNOWLEDGMENT}

The authors gratefully acknowledge the aid of Professor Federico Milano of the University of Castilla-La Mancha, Spain with his valuable comments and suggestions for implementing the new HTG model in PSAT, and for providing PSAT as a FOSS to the power engineering community.

\section{APpendix A \\ AUTHOR's NOTE}

Data of the KTH-NORDIC32 system can be obtained by signing an agreement with the authors. Contacts can be made via the provided e-mail addresses.

\section{APPENDIX B}

DATA

TABLE II

Generator MODEL PARAMETERS

\begin{tabular}{|c|c|c|}
\hline Parameter & Thermal & Hydro \\
\hline \hline$x_{d}$ [p.u.] & 2.2 & 1.1 \\
$x_{d}^{\prime}$ [p.u.] & 0.3 & 0.25 \\
$x_{d}^{\prime}$ [p.u.] & 0.2 & 0.2 \\
$T_{d}^{\prime}$ [p.u.] & 7 & 5 \\
$T_{d 0}^{\prime \prime}$ [p.u.] & 0.05 & 0.05 \\
$x_{q}$ [p.u.] & 2 & 0.7 \\
$x_{q}^{\prime}$ [p.u.] & 0.4 & 0 \\
$x_{q}^{\prime \prime}$ [p.u.] & 0.2 & 0.2 \\
$T_{q 0}^{\prime}$ [p.u.] & 1.5 & 0 \\
$T_{q 0}^{\prime \prime}$ [p.u.] & 0.05 & 0.1 \\
$2 H$ [kWs/kVA] & 12 & 6 \\
\hline
\end{tabular}

TABLE III

EXCITER MODEL PARAMETERS

\begin{tabular}{|c|c|c|}
\hline Parameter & Thermal & Hydro \\
\hline \hline$K_{0}$ [p.u.] & 120 & 50 \\
$T_{2}$ [s] & 50 & 20 \\
$T_{1}$ [s] & 5 & 4 \\
$T_{e}$ [s] & 0.1 & 0.1 \\
$T_{r}$ [s] & 0.001 & 0.001 \\
$v_{f}^{\max }$ [p.u.] & 5 & 4 \\
$v_{f}^{\min }$ [p.u.] & 0 & 0 \\
$v_{f}^{0}$ [p.u.] & 0 & 0 \\
\hline
\end{tabular}

TABLE IV

OVER EXCITATION LIMITER MODEL PARAMETERS

\begin{tabular}{|c|c|}
\hline Parameter & Value \\
\hline \hline$T_{0}$ [p.u.] & 10 \\
$i_{f}^{\lim }$ [p.u.] & $3.0-22.0$ \\
$v_{O X L}^{\max }$ [p.u.] & 1.1 \\
\hline
\end{tabular}

TABLE V

TURBINE GOVERNOR SYSTEM MODEL PARAMETERS: MODEL 1

\begin{tabular}{|c|c|}
\hline Parameter & Value \\
\hline \hline R [p.u.] & 0.04 \\
$T_{g}$ [s] & 5 \\
$T_{c}$ [s] & 0.2 \\
$T_{3}$ [s] & 5 \\
$T_{4}$ [s] & 0.01 \\
$T_{5}$ [s] & 6 \\
$P_{\max }$ [p.u.] & 0.95 \\
$P_{\min }$ [p.u.] & $0,-0.5$ for $G_{13}$ \\
\hline
\end{tabular}

TABLE VI

TURBINE GOVERNOR SYSTEM MODEL PARAMETERS: MODEL 2

\begin{tabular}{|c|c|}
\hline Parameter & Value \\
\hline \hline R [p.u.] & $0.04,0.08$ (for $\left.G_{19}, G_{20}\right)$ \\
$T_{1}$ [s] & 3 \\
$T_{2}$ [s] & 0.5 \\
$P_{\max }$ [p.u.] & 1 \\
$P_{\min }$ [p.u.] & 0 \\
\hline
\end{tabular}


TABLE VII

TURBINE GOVERNOR SYSTEM MODEL PARAMETERS: MODEL 3

\begin{tabular}{|c|c|}
\hline Parameter & Value \\
\hline \hline$T_{g}$ [s] & 0.2 \\
$T_{p}$ [s] & 0.04 \\
$T_{r}$ [s] & 5 \\
$T_{w}$ [s] & 1 \\
$\sigma$ [p.u.] & 0.04 \\
$\delta$ [p.u.] & 0.3 \\
$a_{11}$ [p.u.] & 0.5 \\
$a_{13}$ [p.u.] & 1 \\
$a_{21}$ [p.u.] & 1.5 \\
$a_{23}$ [p.u.] & 1 \\
$G_{\max }$ (Maximum gate opening) [p.u.] & 1 \\
$G_{\min }$ (Minimum gate opening) [p.u.] & 0 \\
\hline
\end{tabular}

\section{REFERENCES}

[1] P. Kundur, J. Paserba, V. Ajjarapu, G. Andersson, A. Bose, C. Canizares, N. Hatziargyriou, D. Hill, A. Stankovic, C. Taylor, T. Van Cutsem, and V. Vittal, "Definition and Classification of Power System Stability IEEE/CIGRE Joint Task Force on Stability Terms and Definitions," IEEE Transactions on Power Systems, vol. 19, no. 3, pp. 1387 - 1401, aug. 2004.

[2] Y. Chompoobutrgool and L. Vanfretti, "Linear Analysis of the KTHNORDIC32 System," KTH Royal Institute of Technology, Tech. Rep. Smarts-Lab-2011-001, March 2011.

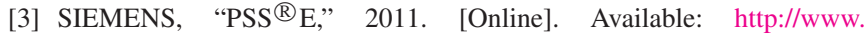
energy.siemens.com/us/en/services/power-transmission-distribution/ power-technologies-international/software-solutions/pss-e.htm

[4] CEPEL, "PacDyn," 2011. [Online]. Available: http://www.pacdyn.cepel. $\mathrm{br} /$

[5] STRI, "SIMPOW," 2011. [Online]. Available: http://www.stri.se/simpow

[6] P. Korba and K. Uhlen, "Wide-area monitoring of electromechanical oscillations in the nordic power system: practical experience," IET Generation, Transmission Distribution, vol. 4, no. 10, pp. 1116 -1126, October 2010.

[7] K. Uhlen, L. Warland, J. Gjerde, O. Breidablik, M. Uusitalo, A. Leirbukt, and P. Korba, "Monitoring Amplitude, Frequency and Damping of Power System Oscillations with PMU Measurements," IEEE PES General Meeting, 2008.

[8] J. Turunen, M. Larsson, P. Korba, J. Jyrinsalo, and L. Haarla, "Experiences and future plans in monitoring the inter-area power oscillation damping," IEEE PES General Meeting, 2008.

[9] N. Chaudhuri, A. Domahidi, R. Majumder, B. Chaudhuri, P. Korba, S. Ray, and K. Uhlen, "Wide-area power oscillation damping control in nordic equivalent system," IET Generation, Transmission Distribution, vol. 4, no. 10, pp. $1139-1150$, October 2010.

[10] E. Johansson, K. Uhlen, A. Leirbukt, P. Korba, J. Gjerde, and L. Vormedal, "Coordinating power oscillation damping control using wide area measurements," IEEE/PES Power Systems Conference and Exposition, pp. 1-8, 2009.

[11] K. Uhlen, S. Elenius, I. Norheim, J. Jyrinsalo, J. Elovaara, and E. Lakervi, "Application of Linear Analysis for Stability Improvements in the Nordic Power Transmission System," IEEE PES General Meeting, pp. 2097-2103, 2003.

[12] R. M. Stallman, Free Software, Free Society: Selected Essays of Richard M. Stallman, 2nd ed. Free Software Foundation, Inc., 2010.

[13] F. Milano, L. Vanfretti, and J. Morataya, "An Open Source Power System Virtual Laboratory: The PSAT Case and Experience," IEEE Transactions on Education, vol. 51, no. 1, pp. 17-23, February 2008.

[14] S. Chopra and D. S. D., Decoding Liberation: The Promise of Free and Open Source Software. Routledge, 2010.

[15] F. Milano, "PSAT, Matlab-based Power System Analysis Toolbox," 2002. [Online]. Available: http://www.power.uwaterloo.ca/ fmilano/ downloads.htm

[16] - "An Open Source Power System Analysis Toolbox," IEEE Trans. Power Syst., vol. 20, no. 3, pp. 1199-1206, August 2005.

[17] W. Li and L. Vanfretti, "Development and Implementation of Hydro Turbine and Governor Models for Small-Signal and Transient Stability Analysis of Power Systems," KTH Royal Institute of Technology, Electric Power Systems Department, Report for: EIT InnoEnergy "Smart Power" Thematic Area, WP3.1: Smart Transmission Grids Real-Time Simulation Platform Smarts-Lab-2011-005, September 2011.
[18] T. Van Cutsem, "Description, Modelling and Simulation Results of a Test System for Voltage Stability Analysis," IEEE Working Group on Test Systems for Voltage stability analysis, Tech. Rep. Version 1, July 2010.

[19] M. C. Stubbe, "Long Term Dynamics Phase II Final Report," Cigre, Tech. Rep. Task Force 38.08.08, March 1995.

[20] T. S. E. Agency, "Energy in Sweden 2010," Tech. Rep., 2010. [Online]. Available: http://webbshop.cm.se/ System/TemplateView.aspx?p=Energimyndigheten\&view=default\&id= b4cea7b00212456b9bdbdbe47a009474

[21] M. Chaudhry, D. Arsenie, and P. Vlase, Applied Hydraulic Transients, 2nd ed. Taylor \& Francis, 1987.

[22] B. Sharp and S. D.B., Water Hammer: Practical Solutions. ButterworthHeinemann, 1996.

[23] W. Li, L. Vanfretti, and Y. Chompoobutrgool, "Development and Implementation of Hydro Turbine and Governors in a Free and Open Source Software Package," Simulation Modelling Practice and Theory, 2011, submitted for publication.

[24] J. Wilkinson, The Algebraic Eigenvalue Problem. Oxford University Press, 2004.

[25] J. H. Chow, Time-scale modeling of dynamic networks with applications to power systems. Springer-Verlag, 1982.

[26] F. Schleif, G. Martin, and R. Angell, "Damping of System Oscillations with a Hydrogenerating Unit," IEEE Transactions on Power Apparatus and Systems, vol. PAS-86, no. 4, pp. 438 -442, April 1967.

[27] F. Schleif and A. Wilbor, "The Coordination of Hydraulic Turbine Governors for Power System Operation," IEEE Transactions on Power Apparatus and Systems, vol. PAS-85, no. 7, pp. 750 -758, July 1966.

[28] D. Kosterev, C. Taylor, and W. Mittelstadt, "Model Validation for August 10, 1996 WSCC System Outage," IEEE Transactions on Powr Systems, vol. 14, no. 3, pp. 967-979, August 1999.

Yuwa Chompoobutrgool received her B.Sc. degree in Electrical Power Engineering from Sirindhorn International Institute of Technology (SIIT), Thailand, in 2006 and M.Sc. degree in Energy Science from Kyoto University, Japan in 2009. Currently, she is a Ph.D. student at KTH Royal Institute of Technology, School of Electrical Engineering, Electric Power Systems, Sweden. Her research interests are stability and control of power systems, particularly wide-area damping control and system modelling.

Wei Li received the B.S. degree in Automation from Beijing Jiaotong University in 2010 and the M.S. degree in Electronics from Mid Sweden University in 2011. She carried out her master thesis on "Hydro Turbine and Governor Modeling and Scripting for Small-Signal and Transient Stability Analysis of Power Syste" at the Electric Power Systems (EPS) division of KTH from January to September 2011, and was awarded the highest assessment mark. At present, she is carrying the project on"Evaluation of Modelica-Based power system modeling tools for off-line simulation and realtime simulation" at the EPS division of KTH.

Luigi Vanfretti(M'10) is an Assistant Professor at the Electric Power Systems Division, School of Electrical Engineering, KTH Royal Institute of Technology, Stockholm, Sweden. He obtained the Electrical Engineering Degree (with a Power Engineering concentration) from Universidad de San Carlos de Guatemala in June 2005. During Fall 2005, he was a visiting researcher at the Department of Electronics and Electrical Engineering of The University of Glasgow, Scotland. He received his M.S. in 2007 and Ph.D. in 2009, both in Electric Power Engineering, from Rensselaer Polytechnic Institute. His research interests are modeling, dynamics, stability and control of power systems; applications of PMU data, and open source software for power system engineering education. 